\title{
Trabajadoras domésticas nicaragüenses en Costa Rica: un tortuoso camino hacia el reconocimiento
}

\begin{abstract}
Alexandra Bonnie
Organización Internacional para las Migraciones (OIM). Ofiplaza El Retiro, Edificio 5, Suite 522. De la Rotonda del Periodista $150 \mathrm{mts}$. al Sur, Managua, Nicaragua. Tel. (505) 2278 9569, correo electrónico: abonnie@iom.int
\end{abstract}

Recibido: septiembre de 2010 / Aceptado: octubre de 2010

EL TRABAJO DOMÉSTICO ES UN SECTOR HISTÓRICAMENTE VULNERABLE: se considera a menudo como precario, mal retribuido, inseguro y desprotegido. Los y las trabajadores/as domésticos/as sufren discriminación, aún más cuando son mujeres y extranjeros. El presente artículo pretende estudiar las condiciones laborales de las trabajadoras domésticas en Costa Rica frente a dos importantes evoluciones jurídicas recientes: la reforma del capítulo VIII del Código de Trabajo, relativo al trabajo doméstico remunerado, en 2009, y la entrada en vigor de la nueva Ley General de Migración y Extranjería, en 2010, que afecta a las trabajadoras domésticas migrantes. Como en otros países, las trabajadoras domésticas nacionales y migrantes se organizaron para obtener el reconocimiento de sus derechos laborales, lo que se concretó en el año 2009 con la reforma del Código de Trabajo, considerado como discriminatorio. Esto fue un gran paso para el mejoramiento de su condición, y se destaca el rol importante que tuvo la Asociación de Trabajadoras Domésticas (ASTRADOMES). Sin embargo, la modificación de la normativa no se concreta de igual manera para todas las trabajadoras domésticas. Persisten situaciones de vulnerabilidad y abusos, sobre todo en el caso de las trabajadoras migrantes nicaragüenses. Ello conduce a plantear la necesidad de implementar una política pública integral que atiende a las necesidades de las personas cualquiera sea su nacionalidad y estatus migratorio. El estudio está basado en el análisis de fuentes secundarias tanto académicas como jurídicas. Se complementó la información con entrevistas semiestructuradas a informantes clave, incluyendo a representantes de trabajadoras domésticas.

Palabras clave: trabajadoras domésticas / derechos laborales / migración nicaragüense / Costa Rica / ASTRADOMES

\section{Introducción}

Desde hace dos años la crisis económica global impacta todos los sectores, incluso el servicio doméstico que, en el caso latinoamericano, se contrajo un 4.1 \% en 2008 (Organización Internacional del Trabajo [OIT], 2009). Al igual que todos sus vecinos, Costa Rica fue 
duramente afectada por dicha contracción. Sin embargo, no se observó una reducción del empleo en el sector doméstico. El debate sobre el trabajo doméstico en este país no gira en torno a su disminución, sino más bien a la mayor regulación del sector. A nivel internacional, la tradicional invisibilidad e informalidad que rodea el trabajo doméstico remunerado (Lerussi, 2008) también pareciera estar cambiando, como lo demuestra el renovado interés de la Organización Internacional del Trabajo (OIT) en formular un instrumento internacional de protección de los derechos de los y las trabajadores/as domésticos/as. La OIT pretende reconocer a los y las trabajadores/as domésticos/as como trabajadores iguales a los demás (OIT, 2010a).

En Costa Rica el 12\% de la población ocupada femenina labora en el servicio doméstico (OIT, 2006). Este es un sector en aumento estructural por los cambios en la organización del trabajo (creciente tasa de incorporación laboral femenina), el envejecimiento de la población y la menor atención del Estado a través de los servicios sociales (OIT, 2010a). Esa creciente demanda de trabajadoras domésticas se ha visto satisfecha gracias a los y las migrantes provenientes de países vecinos, particularmente de Nicaragua. De hecho, el trabajo doméstico ha sido un nicho de mayor acceso para las migrantes nicaragüenses en Costa Rica, y se ha mantenido el fenómeno en tiempos de crisis al aumentar la presión sobre las mujeres para garantizar la subsistencia familiar (Lerussi, 2008). Al buscar cual es la proporción de migrantes en el sector del trabajo doméstico, las cifras son muy variables: se suele considerar que más de la mitad de las 130.000 trabajadoras domésticas son extranjeras, principalmente nicaragüenses (Biffi, 2009). Sin embargo, una reciente investigación de UNIFEM (Fondo de las Naciones Unidas para la Mujer [UNIFEM], 2010) alega que ese importante peso comúnmente aceptado es falso: aún tomando en cuenta el sub-registro debido al alto porcentaje de personas irregulares, esta fuente estima en 22.246 el número de trabajadoras domésticas nicaragüenses en el país, lo que corresponde al 17.1\% del total.

En el contexto del presente artículo no es de interés la cuantificación del fenómeno del trabajo doméstico sino el análisis de las condiciones de las trabajadoras domésticas migrantes frente a dos evoluciones jurídicas recientes en Costa Rica: la reforma del capítulo VIII del Código de Trabajo, relativo al trabajo doméstico remunerado, en julio de 2009 y la entrada en vigor de la nueva Ley General de Migración y Extranjería, en marzo de 2010. La reforma del capítulo octavo del Código de Trabajo responde a una demanda histórica de las propias trabajadoras domésticas, organizadas en la Asociación de Trabajadoras Domésticas (ASTRADOMES). Esta asociación nació en 1991 para defender a las trabajadoras domésticas y obtener una revisión de la legislación vigente, la cual establecía una desigualdad de trato respecto a los demás trabajadores. Si bien la reforma del Código de Trabajo se puede considerar como un gran avance para el reconocimiento de los derechos laborales de las trabajadoras domésticas, ésta no impacta del mismo modo a las trabajadoras migrantes. Las trabajadoras domésticas, cuando son extranjeras, deben adaptarse además a las normas establecidas por la nueva Ley General de Migración y Extranjería, Ley $\mathrm{N}^{\circ} 8764$ publicada en La Gaceta $\mathrm{N}^{0} 170$ el 1 de septiembre de 2009 (Asamblea Legislativa de Costa Rica, 2009b). Ambas normas -laboral y migratoria- buscan mejorar las condiciones de los trabajadores, sean nacionales o migrantes. Sin embargo, en la realidad persisten dificultades no contempladas por los legisladores, que llaman a una profundización del marco jurídico por programas 
de atención específica a fin de garantizar una igualdad de trato real y un reconocimiento social. En ese sentido, es evidente que hay que ir un paso más allá en la protección de las trabajadoras domésticas migrantes -doblemente vulnerables, por su condición laboral y por su nacionalidad-, con la implementación de políticas públicas enfocadas en sus necesidades específicas e inspiradas en la futura norma internacional para su protección, que se adoptará en junio de 2011.

\section{Hacia el reconocimiento de un sector tradicionalmente discriminado}

Las trabajadoras domésticas migrantes en Costa Rica reportan sentirse desvalorizadas socialmente y haber vivido en las últimas décadas una discriminación legalizada por una normativa vigente desde el año 1943, que autorizaba jornadas de doce horas y les negaba el derecho a un día de descanso semanal. Este hecho se agudizó en los años noventa con el aumento del número de trabajadoras domésticas migrantes, momento en que empezaron a organizarse para poner el tema en la agenda política costarricense y obtener una reforma del Código de Trabajo. Esta batalla duró veinte años e involucró a innumerables actores.

\subsection{Una larga lucha en contra de la desprotección y discriminación}

El trabajo doméstico remunerado, definido como "prestación remunerada de cuidados y servicios de limpieza en el hogar" (OIT, 2010a, p. 4), suele ser considerado una de las actividades económicas más precarias y desprotegidas. El trabajo doméstico difiere en ciertos aspectos de las otras categorías laborales, y las características de esta categoría son en parte socialmente desvalorizadas, lo que participa de la falta de protección de las trabajadoras domésticas. La vulnerabilidad jurídica y social que sufren los y las trabajadores/ as domésticos/as encuentra una primera explicación en el lugar donde se desempeña el trabajo doméstico remunerado: el hogar. El hecho de darse en un ámbito privado dificulta las inspecciones del trabajo, mientras estas inspecciones se consideran como una potencial garantía en contra de las violaciones de los derechos laborales (OIT, 2010a). Esa diferencia no es ajena al poco valor asociado a este tipo de trabajo: en efecto se suele cuestionar su "productividad", dado que está asociado con el trabajo "tradicional" de las mujeres (que se desarrollaría en el ámbito privado también), el cual no es remunerado por pertenecer a la esfera reproductiva, en oposición a la esfera económica-productiva (considerada como pública, por lo tanto fuera del hogar) (Lerussi, 2008). Por su supuesta baja productividad, el salario de las trabajadoras domésticas en Costa Rica sigue siendo uno de los más bajos, a pesar de las extensas jornadas que cumplen (a veces hasta 14 horas) (Fernández \& Acosta, 2009). Las tareas que deben realizar pueden ser muy amplias, y no todas son remuneradas a su justo valor, como es el caso del trabajo afectivo que se espera muchas veces de ellas, cuando se les encarga el cuidado de niños o personas mayores (Goldsmith, 2007). En definitiva, es un trabajo "en la frontera" entre lo laboral y lo afectivo, entre lo público y lo privado (UNIFEM, 2010).

La naturaleza del trabajo no facilita, por lo tanto, la organización de las trabajadoras domésticas para reivindicar sus derechos, obtener mejores condiciones laborales y el debido reconocimiento social. Suelen ser mujeres aisladas. De hecho, muchas trabajan todavía con "cama adentro", aunque la concentración de los estudios sobre esta última categoría 
no debe esconder la importancia creciente de las trabajadoras domésticas que realizan jornadas parciales, contratadas por horas en diversas casas (Paniagua, 2007), ya que 6 de cada 10 realizan jornadas parciales (UNIFEM, 2010).

Sin embargo, la discriminación legalmente establecida en contra de las trabajadoras domésticas llevó a una cierta movilización en Costa Rica. A pesar de lo comúnmente establecido, este movimiento no es tan reciente: ya en el año 1964 se aprobó una reforma del capítulo VIII del Código de Trabajo de 1943 sobre las trabajadoras domésticas gracias a las acciones de la Asociación de Servidoras Domésticas de Costa Rica ${ }^{1}$ (Lerussi, 2008). Efectivamente, la normativa en vigor establecía una discriminación en cuanto a la remuneración: las trabajadoras domésticas eran los únicos trabajadores que podían percibir un salario en especie (Art. 102), bajo lo cual se entiende el alojamiento y la alimentación, y que se prestaba a abusos como la trata de personas y el trabajo infantil. Por otra parte, el artículo 103 autorizaba una jornada laboral de hasta 14 horas, cuando el resto de los trabajadores ya gozaban de la jornada de ocho horas (UNIFEM, 2010). Además, las trabajadoras domésticas no fueron incluidas en la definición del descanso semanal, ni en el acceso a días feriados, como los demás trabajadores.

La reforma del año 1964, promovida por la mencionada Asociación, mejoró las condiciones de las trabajadoras domésticas en cuanto a la reducción de la jornada laboral de 14 a 12 horas y al establecimiento de la jornada extraordinaria a cuatro horas. Se autorizó además un medio día de descanso semanal y quince días de vacaciones remuneradas (UNIFEM, 2010).

Estos avances mejoraron efectivamente la situación de las trabajadoras domésticas en el país, pero no eliminaron todas las discriminaciones legalmente establecidas. Esa situación se agudizó en los años ochenta y noventa cuando aumentó la importancia económica y social del trabajo doméstico en el contexto de restructuración de la economía costarricense caracterizada principalmente por el incremento de las mujeres en la fuerza laboral y el desarrollo del sector servicios. Paralelamente a ello, el país conoció en los años noventa un movimiento para el reconocimiento de los derechos de las mujeres y, por otra parte, aumentó de manera significativa la inmigración nicaragüense, especialmente de mujeres. En este contexto nació la Asociación de Trabajadoras Domésticas ${ }^{2}$ (ASTRADOMES), reivindicando desde su inicio la equiparación del trabajo doméstico con cualquier otro trabajo en cuanto a los derechos laborales, eliminando todo tipo de discriminación jurídica que las perjudique (Lerussi, 2008).

Sin embargo, esta demanda no correspondía con la agenda política, en donde el tema del trabajo doméstico estaba ausente a pesar del empeoramiento de las condiciones de trabajo de las trabajadoras domésticas, en particular de las recién llegadas, a menudo sin documentos. Las reformas introducidas en el Código de Trabajo en 1964 no respondían a las expectativas del movimiento, sin mencionar que la norma era contraria al Convenio 111 de la OIT relativo a la discriminación en materia de empleo y ocupación, ratificado desde 1962 por Costa Rica. Este convenio establece la igualdad de trato como un derecho de los trabajadores y una obligación de los empleadores y Estados de asegurarla (OIT, 1958). Fue precisamente la cuestión de la igualdad de trato que llevó a ASTRADOMES a presentar 
una acción de inconstitucionalidad ante la Sala Constitucional de la Corte Suprema de Justicia en relación al artículo 104 del Código del Trabajo (relativo a la jornada laboral, los días de descanso y feriados), el 24 de noviembre de 2005. Esta acción judicial consideraba que daba un trato diferenciado a las trabajadoras domésticas que les perjudicaba (Fernández \& Acosta, 2009). En marzo de 2007 la Sala Constitucional estableció el derecho de las trabajadoras domésticas a un día completo de descanso semanal y el derecho a disfrutar los días feriados nacionales. Además, declaró inconstitucional la posible división en fracciones de la jornada laboral, que permitía extenderla hasta 15 horas diarias (Fernández \& Acosta, 2009). Sin embargo, la Sala Constitucional desestimó el punto considerado como más importante del recurso presentado por ASTRADOMES: la homologación del horario de la jornada ordinaria con los demás trabajadores.

Esa decisión fue una etapa relevante que permitió ubicar el tema en la agenda política, y por ende, llegar a una reforma de la ley laboral vigente en el año 2009, ante la perspectiva de que ASTRADOMES acudiera a la Comisión Interamericana de los Derechos Humanos (CIDH) (Fernández \& Acosta, 2009).

\subsection{La reforma del Código de Trabajo en 2009: un avance determinante}

El 24 de julio de 2009 se publica en La Gaceta de Costa Rica la Ley No. 8726, mediante la cual la Asamblea Legislativa reforma el Código de Trabajo (1943) en su capítulo VIII "Trabajo doméstico remunerado" (Asamblea Legislativa de Costa Rica, 2009a). Esta reforma responde a las demandas formuladas por ASTRADOMES y las trabajadoras domésticas en general, desde hacía más de quince años.

La exigencia principal de las trabajadoras domésticas giraba en torno a la jornada laboral, se pretendía reducirla de doce a ocho horas, lo que provocaba una gran inquietud por parte de los empleadores quienes se preguntaban cómo iban a cubrir su jornada y cuánto les iba a costar en concepto de horas extras (Fernández \& Acosta, 2009). La nueva Ley responde a esta demanda central, estableciendo la jornada laboral a ocho horas diurnas (al igual que los demás trabajadores) y seis horas nocturnas (Art. 105): se permiten jornadas de 10 horas, pero siempre y cuando no se exceda de las 48 horas semanales.

Por otra parte, la reforma cumple con las demandas en cuanto a la distinción entre remuneración en efectivo y en especie: el artículo 105 establece el derecho de las trabajadoras domésticas a cobrar en efectivo el salario mínimo (que corresponde a la categoría establecida por el Consejo Nacional de Salarios). El salario en especie sigue existiendo (alojamiento y alimentación "adecuados"), pero debe estipularse en el contrato laboral y no podrá formar parte "en ninguna circunstancia” del rubro del salario mínimo (Art. 105 a).

Otro punto que tiene su importancia es la definición que se propone del trabajo doméstico: es un avance real porque establece una delimitación de las tareas que le compete a un/a trabajador/a doméstico/a:

Las personas trabajadoras domésticas son las que brindan asistencia y bienestar a una familia o persona, en forma remunerada; se dedican, en forma habitual y sistemática, a 
labores de limpieza, cocina, lavado, planchado y demás labores propias de un hogar, residencia o habitación particular, que no generan lucro para las personas empleadoras (...) (Art.101, Código de Trabajo).

Es más, el cuidado ya no se considera como una tarea inherente al trabajo doméstico: debe resultar de un acuerdo entre las partes:

(...) también pueden asumir labores relativas al cuidado de personas, cuando así se acuerde entre las partes y éstas se desarrollen en la casa de la persona atendida (Art.101, Código de Trabajo).

Todo ello adquiere mucha más importancia ya que debe ser estipulado en el contrato de trabajo, en adelante, escrito (Art. 101). El contrato por escrito es un avance que responde a recomendaciones académicas e incluso al proyecto de Convenio sobre las trabajadoras domésticas de la OIT (Art. 6). En materia de seguridad social, la reforma establece el deber por parte de los patronos de garantizarla a sus empleados domésticos, lo que incluye la obligación de inscribirles a la Caja Costarricense de Seguro Social (CCSS) dentro de los ocho días hábiles siguientes al inicio de su contrato (Art.104). Las trabajadoras domésticas tienen en adelante derecho a un día de descanso por semana, y debe ser un domingo por lo menos dos veces al mes (Art. 105 b). En cuanto a las vacaciones, tendrán derecho a quince días remunerados, sólo cuando hayan trabajado cincuenta semanas. Finalmente, se extiende el periodo de prueba de uno a tres meses, aunque eso no es suficiente garantía ya que durante este lapso de tiempo los empleadores pueden despedir a las trabajadoras domésticas sin aviso previo (Art. 102).

A pesar de esa última limitación, se puede considerar que la reforma del capítulo VIII del Código de Trabajo respondió a casi todas las demandas de las trabajadoras domésticas, motivo por el cual fue considerada como una victoria histórica (Biffi, 2009).

\subsection{Más allá de lo jurídico: el valor simbólico de la victoria}

Si bien es cierto que la reforma legal del año 2009 mejora sustancialmente las condiciones laborales de las trabajadoras domésticas, la promotora de ASTRADOMES $^{3}$ estima que la diferencia más relevante respecto al pasado es a nivel simbólico. Por primera vez las trabajadoras domésticas, incluso las extranjeras, se sienten protegidas por la Ley y reconocidas a nivel social. Es decir, la reforma tuvo un impacto directo en la autoestima de las trabajadoras que vieron sus demandas escuchadas.

Por haber tenido un rol protagónico en el proceso de aprobación de la reforma -en el que las trabajadoras domésticas organizadas rompieron con los tradicionales estereotipos que les rodean: la victimización, o invisibilidad en el mejor de los casos-, ASTRADOMES ${ }^{4}$ puede ser considerada como un grupo de presión (Goldsmith, 2007). Al organizarse en asociación, por un lado se creó una identidad común que les ayudó a salir del aislamiento tradicional que conocían y, por otro, se fortaleció su auto-estima, al ganar la batalla por sus derechos laborales. 


\section{Del Parlamento al hogar: el largo camino de una reforma}

Un año después de la aprobación de la reforma del Código de Trabajo en su parte relativa al trabajo doméstico, sería sin duda muy prematuro hacer un balance definitivo y sacar conclusiones sobre su aplicación. Sin embargo, puede ser interesante valorar las opiniones de las trabajadoras domésticas migrantes una vez pasado el primer momento de entusiasmo, y analizar los primeros cambios concretos en su vida, en especial, a la luz de otro cambio legislativo que les afecta directamente como trabajadoras migrantes: la entrada en vigor de la nueva Ley General de Migración y Extranjería, en marzo de 2010.

Esta sección está basada en el análisis de informaciones suministradas por las líderes de ASTRADOMES durante una entrevista semi-estructura y fue contrastada con entrevistas y consultas a varios informantes clave ${ }^{5}$.

\subsection{Las dificultades de cumplimiento del nuevo capítulo VIII del Código de Trabajo: una labor necesaria de información y sensibilización}

La evolución de la legislación no siempre se corresponde con la evolución de la opinión pública en general, o con las prácticas de los principales actores involucrados, en particular: algunas veces una adelanta a la otra y viceversa. En el caso del trabajo doméstico ya se ha hecho un análisis de la percepción de este tipo de trabajo en la sección anterior (social y económicamente desvalorizado, considerado como naturalmente femenino, descalificado e improductivo). Esta percepción empeora cuando el trabajo es realizado por personas migrantes, quienes sufren la discriminación y xenofobia de algunas personas.

Esos estereotipos, esos años de invisibilidad y discriminación legalizada, no pueden cambiarse a corto plazo por la amplitud y ancianidad del fenómeno. Existe un amplio desconocimiento de los derechos laborales recién obtenidos, tanto por parte de las mismas trabajadoras domésticas como de sus empleadores/as, que "agudiza la vulnerabilidad objetiva y subjetiva de las trabajadoras domésticas" (Fernández \& Acosta, 2009, p.19). Así, ASTRADOMES reporta haber conocido desde la entrada en vigor de la nueva Ley un incremento significativo de consultas de trabajadoras domésticas y empleadores para obtener mayor información sobre los derechos de las primeras. Muchos/as empleadores/as acuden a la Asociación porque desconocen la ley, y no dan crédito a alegaciones de nuevos derechos laborales ${ }^{6}$.

Un obstáculo importante para la aplicación de la ley es la falta de divulgación, lo que confirman todas las fuentes consultadas. En este sentido, ASTRADOMES, siguiendo con su labor de sensibilización, publicó un librito para las trabajadoras domésticas, donde se explican sus nuevos derechos laborales. Tiene también pendiente la publicación de otro material para los/as empleadores/as, pero más amplio, que comprenderá toda la legislación vigente. En este tema resulta de hecho importante la labor de divulgación que realizan las organizaciones representantes de trabajadoras domésticas por su cercanía con las mismas trabajadoras. Pero los resultados podrían ser potenciados al desarrollarse en el marco de una campaña de sensibilización pública a nivel nacional. 
Además, ya se identifican varias faltas de aplicación de la reforma. La mayor parte de los abusos se producen por la práctica de los empleadores de contratar verbalmente evitando el contrato por escrito. Esa violación abre la puerta a otros abusos ya prohibidos por la Ley, como por ejemplo, el irrespeto de la delimitación de las tareas. Muchas trabajadoras domésticas asumen por el mismo salario el rol de niñeras y/o cuidado de personas mayores, según ASTRADOMES. Por otra parte, si bien las trabajadoras domésticas reciben el salario mínimo (128.526,79 colones, aproximadamente USD 2567), siguen ganando menos que la mayoría de los trabajadores, incluso aquellos trabajadores no calificados $(214.698,89$ colones, USD429) (Ministerio de Trabajo y Seguridad Social [MTSS], 2010). Su jornada laboral es ahora de ocho horas y pagada según el salario mínimo, pero las trabajadoras han reportado que ciertos empleadores compensan su "pérdida" aumentando el número de tareas que deben cumplir durante la jornada laboral.

Otra dificultad comentada por las trabajadoras domésticas a ASTRADOMES es el salario en especie: la ley dejó más claras las obligaciones de cada parte, pero siguen existiendo casos en los cuales los empleadores niegan a sus trabajadoras domésticas el pago en efectivo del salario en especie cuando están de vacaciones o en caso de despido. Parece que los legisladores se dieron cuenta de la necesidad de complementar ese punto, ya que propusieron un proyecto de Ley (Adición de un párrafo final al inciso a) del artículo 105 del Código de Trabajo. Expediente $\mathrm{N}^{\circ}$ 17.689. La Gaceta $\mathrm{N}^{\circ}$ 156. Jueves 12 de agosto del 2010), "con el propósito de que no haya duda sobre la voluntad del legislador, (...) a fin de evitar malos entendidos en lo que se refiere al "salario en especie", en particular, con las servidoras domésticas, así como para efectos de pago en caso de liquidación laboral por mutuo acuerdo o por despido injustificado y, también, en cuanto al pago anual del aguinaldo". El proyecto de Ley agrega que "el salario en especie se estimará como el cincuenta por ciento (50\%) del salario ordinario, para efectos de cálculo de pago de aguinaldo o para liquidación de la relación laboral, por causa de despido injustificado o por mutuo acuerdo de las partes" (Asamblea Legislativa, 2010, p. 9).

Por otra parte, la reforma tuvo un impacto imprevisto en cuanto a la afiliación al sistema de seguridad social costarricense, obligatoria según el artículo 104 del Código. Ésta era una de las reivindicaciones más importantes de ASTRADOMES, dado que antes de la entrada en vigor de la reforma, las trabajadoras domésticas eran excluidas del derecho a la salud y una pensión por no ser inscritas por sus empleadores en los regímenes de protección y seguridad social: 9.400 trabajadoras domésticas eran aseguradas en el año 2009, es decir el 7\% (EIRENE, 2010). Frente a la obligación de inscribir a las trabajadoras domésticas en la Caja Costarricense del Seguro Social (CCSS), los representantes de asociaciones entrevistados reportan que una parte de los/as empleadores/as "incentiva" a sus empleadas a contratar un seguro voluntario, alegando que el porcentaje cobrado sobre su salario será menor que los 9\% exigidos para la afiliación al seguro obligatorio de la CCSS. Ahora bien, el seguro voluntario no cubre nada más que el riesgo de enfermedad, por lo cual representa una protección incompleta para las trabajadoras, además de constituir una "manipulación patronal" según la directora del Servicio Jesuita para Migrantes de Costa Rica, en cuanto permite a las y los empleadores evadir sus responsabilidades ${ }^{8}$ al promover una forma de seguro que no contempla la relación laboral empleador - asalariado. Este fenómeno podría explicar el aumento muy moderado de las inscripciones patronales por servicios domésticos, que crecieron un 88\% en 2010, en comparación con el mismo periodo de 2009: “se pasó de 432 
inscripciones acumuladas entre enero y abril de 2009 a 815 este año" según Odalie Arias, directora de Inspección de la Caja (Villegas, 2010), cantidad relativamente baja respecto al total de las trabajadoras domésticas.

\subsection{Una de cal y otra de arena para las trabajadoras domésticas migrantes}

El acceso a la seguridad social es un buen ejemplo para demostrar que la reforma no afecta del mismo modo a las trabajadoras domésticas costarricenses y a las trabajadoras domésticas extranjeras, en particular si están laborando de manera irregular, a pesar de que, como toda norma, el Código de Trabajo rige para todos los habitantes, sin importar la residencia ni el estatus migratorio. De aplicarse ésta, las trabajadoras domésticas migrantes deberían estar todas afiliadas a la CCSS, ya que esta obligación recogida en la normativa laboral se ve repetida en la nueva Ley General de Migración y Extranjería, que entró en vigor el $1^{\circ}$ de marzo de 2010. Esta Ley establece efectivamente como requisito para obtener un permiso de trabajo y la residencia, la cotización a la CCSS. En Costa Rica se estima que el $57 \%$ de las trabajadoras nicaragüenses son irregulares -aunque no sean todas trabajadoras domésticas (Contreras, 2006).

A pesar de la entrada en vigor de esas dos normativas que buscan proteger al trabajador, la vulnerabilidad de las trabajadoras domésticas migrantes se agudizó respecto al tema de la seguridad social. Según comentó ASTRADOMES, les pueden afectar de varios modos. En el mejor de los casos, los empleadores aceptan prestarles el monto necesario para cambiar su situación migratoria, contrayendo una deuda elevada con éstos. Efectivamente, el costo y los obstáculos para un trabajador migrante que quiere regularizar su situación desde Costa Rica son altos: se debe considerar los costos de cambio de categoría migratoria (200 dólares por el artículo 89 de la ley 8764), los costos de transporte entre ambos países necesarios para conseguir y validar diversos documentos (partida de nacimiento, cédula de identidad, etc.) y los costos de dichos documentos. Ello implica para las empleadas domésticas pedir un permiso de trabajo a sus empleadores, el cual se suele dar los fines de semana, cuando están cerradas las oficinas de Migración (Patiño, Solís, \& Galo, 2008). Considerando esos costos, hay trabajadoras domésticas que se mantienen en condición de irregularidad migratoria. Otras son despedidas por empleadores que no quieren asumir el costo de su regularización: una parte piensa regresar a Nicaragua, pero la mayoría busca alternativas informales como la venta callejera, según observa la promotora de ASTRADOMES. Sin embargo, las diferentes fuentes consultadas no consideran esas dos "opciones" como fenómenos masivos, lo que concuerda con las conclusiones del estudio sobre el retorno de los nicaragüenses de EIRENE (2010). A pesar de los obstáculos, las trabajadoras domésticas migrantes prefieren asumir los costos de la regularización, incluso los costos que competerían a sus empleadores.

Lamentablemente, cuando se presentan los casos abusivos mencionados, no existen muchos recursos frente a ello. A pesar de que los trabajadores migrantes adquieren sus derechos laborales por la existencia de una relación laboral y no por su condición o estatus migratorio $^{9}$, en Costa Rica no hay muchas posibilidades de queja para los trabajadores migrantes ya que necesitan su cédula de residencia o un pasaporte vigente para poder defenderse en el tribunal (Guerrero \& Lacayo, 2008). Tampoco con la residencia es fácil el acceso a la justicia laboral: 
Lo que pasa con la población migrante es que se le violentan los derechos; se violentan los de las costarricenses también, pero ellas tienen más facilidad porque saben del ministerio, saben defenderse mejor, pero para la población migrante es más difícil, aunque esté documentada les da miedo ir a reclamar, indocumentada menos" (Rosita Acosta, fundadora de ASTRADOMES, citada por Goldsmith, 2007, p.14).

Además, con esa nueva normativa migratoria, las trabajadoras domésticas irregulares no temen sólo ser arrestadas y deportadas, sino también tener que pagar una multa de cien dólares por mes de estancia irregular (Art. 33.3 de la ley 8764). Dicha situación no facilita la reivindicación de sus nuevos derechos laborales frente a su empleador.

\section{Reflexiones finales: la necesidad de ir más allá de la protección legal}

Frente a los obstáculos encontrados aún por las trabajadoras domésticas, especialmente las extranjeras, se destaca la necesidad de aportar una respuesta más integral a través de una política pública centrada en la protección de los derechos de las trabajadoras domésticas pero también en el fortalecimiento de sus capacidades. En este sentido, puede servir como fuente de inspiración el Proyecto de Convenio sobre el Trabajo Decente para (los trabajadores domésticos) (las trabajadoras y los trabajadores domésticos) (las trabajadoras y los trabajadores del hogar) ${ }^{10}$ que está elaborando la OIT (OIT, 2010b) y aprovechar, en caso de que sea aprobado, el poder de presión que supone un instrumento internacional.

\subsection{Un desafío político compartido}

La reforma de la norma jurídica obtenida por las trabajadoras domésticas en Costa Rica puede considerarse como un avance esencial hacia el reconocimiento de este sector tradicionalmente discriminado y víctima de explotación laboral. Aunque conlleva algunas fallas, aumenta la protección jurídica de las costarricenses como de las extranjeras. Pero esa protección podría ser potenciada por una verdadera política pública, como lo recomienda también el reciente estudio de UNIFEM (2010). Consideramos que se trata de un desafío político compartido en la medida que las mismas trabajadoras domésticas deberían de ser integradas como actoras del cambio, o por lo menos las asociaciones que les representan. Ya se mencionó como acción necesaria la divulgación de los derechos laborales; otro de los ejes en donde se puede actuar conjuntamente es el de la capacitación laboral y de la certificación de competencias de las trabajadoras domésticas, por ejemplo, en materia de cuidado de personas mayores. Como todos los trabajadores, las trabajadoras domésticas deberían de tener la oportunidad de seguir formándose a través de métodos educativos alternativos.

Otro rubro importante es la protección social: para aumentar la cobertura del aseguramiento, UNIFEM (2010) sugiere el reconocimiento de la jornada parcial en las contribuciones que realiza el empleador y la trabajadora a la Seguridad Social, así como en el caso del pago por parte de dos o más empleadores de una misma trabajadora doméstica. Para luchar contra la informalidad del trabajo doméstico, Costa Rica podría considerar también el cheque de servicios, sistema adoptado en varios países (Francia, Austria, Canadá, etc.). Este mecanismo facilita el cálculo de las retenciones obligatorias y puede contribuir al pago de los servicios prestados, además de reducir los costos de transacción tanto para los empleadores como para los trabajadores (OIT, 2010a). 
En la implementación de la política pública para las trabajadoras domésticas, ASTRADOMES podría ser una valiosa aliada, dada su representatividad y experiencia previa. Sin embargo, existe un debate abierto, ya que unos cuestionan si este tipo de organización es el que más beneficia a las trabajadoras domésticas, al considerarse que la asociación puede frenar las posibilidades para la sindicalización de este sector, y que un sindicato podría tener un mayor impacto en las negociaciones con el gobierno (Goldsmith, 2007). Sin embargo, ASTRADOMES se niega a transformarse en un sindicato, a fin de asegurar la representatividad de todo el sector doméstico en su junta directiva: tanto las nacionales como las extranjeras. La Constitución Política del País establece en su artículo 60 que "queda prohibido a los extranjeros ejercer dirección o autoridad en los sindicatos" - lo que viola las normas internacionales, claramente el Convenio de la OIT sobre la libertad sindical y la protección del derecho de sindicación ${ }^{11}$ (C.87, 1948), por lo cual no quiere cambiar de estatus la asociación, ya que quiere seguir integrando en su junta directiva a representantes de las trabajadoras domésticas extranjeras (actualmente son dos costarricenses y cuatro nicaragüenses). Se nota que esta cláusula restrictiva sólo concierne a las funciones de dirección: la Constitución no prohíbe a los/las trabajadores/as migrantes ser miembros de una organización sindical, aunque no se establezca de manera explícita este derecho reconocido por la Convención Internacional sobre la Protección de los Derechos de Todos los Trabajadores Migratorios y de sus Familiares (Art. 26) ${ }^{12}$.

\subsection{Pensando en el futuro: un instrumento internacional para las trabajadoras domésticas}

Los avances conseguidos por las trabajadoras domésticas en Costa Rica son aún más relevantes cuando se tiene en cuenta que no pudieron apoyarse en un instrumento de protección internacional, ya que al día de hoy no existe:

Las normas internacionales del trabajo existentes no ofrecen directrices adecuadas sobre el modo de garantizar una protección significativa para los trabajadores del servicio doméstico, ya que, o no tratan el contexto específico en el que se presta este tipo de servicio, o permiten su exclusión explícita (OIT, 2010a, p. 6)

Sin embargo, se puede observar un interés renovado de la OIT en este tema, 45 años después de la adopción de una primera resolución sobre las condiciones de empleo de los trabajadores domésticos (OIT, 1965). En 2008, el Consejo de Administración de la Organización, en su $301^{\mathrm{a}}$ reunión, inscribió el tema en el orden del día de la $99^{\mathrm{a}}$ reunión de la Conferencia Internacional del Trabajo, que tuvo lugar en junio de 2010. Se discutió en esa Conferencia la conveniencia y la forma de un posible instrumento internacional, a partir del informe preliminar sobre el trabajo decente para los trabajadores domésticos que elaboró la Oficina con este fin (Informe IV, OIT, 2010b). Siguiendo a las recomendaciones de dicho informe, los Estados Miembros de la OIT, y los representantes de los empleadores y de los trabajadores reunidos en la Conferencia, propusieron un proyecto de convenio y su recomendación, del cual se pueden obtener también unas recomendaciones preciosas para el caso costarricense.

El proyecto de convenio enfatiza el tema de la igualdad de trato de las trabajadoras domésticas con los demás trabajadores (como lo había hecho anteriormente la OIT con los trabajadores 
migrantes), y se menciona claramente que muchos de los trabajadores domésticos suelen ser mujeres y migrantes, distinción que no es visible en la norma costarricense. El Estado debe adoptar medidas para asegurar una protección efectiva de los derechos humanos: el borrador detalla, por ejemplo, cada punto que debería especificarse en el contrato de trabajo, así como las condiciones de alojamiento y alimentación, para evitar abusos. El artículo 7 prevé que los y las trabajadores/as domésticos/as migrantes deberían recibir este contrato antes de pasar la frontera nacional. También se establece la necesidad de fomentar el desarrollo continuo de las competencias y calificaciones para mejorar las perspectivas de las trabajadoras domésticas.

Finalmente, la propuesta de convenio menciona la cooperación interestatal y el rol que deben jugar los países de origen (como es el caso de Nicaragua):

Los Miembros que son países de origen de (los trabajadores domésticos) (las trabajadoras y los trabajadores domésticos) (las trabajadoras y los trabajadores del hogar) migrantes deberían contribuir a la protección efectiva de los derechos de (estos trabajadores) (estas trabajadoras y trabajadores), informándoles acerca de sus derechos antes de salir de su país, creando fondos de asistencia jurídica, servicios sociales y servicios consulares especializados y adoptando toda otra medida que sea apropiada (Informe IV, OIT, 2010b, p.23).

Esa recomendación podría ser desarrollada en el marco del acuerdo binacional firmado por Costa Rica y Nicaragua para la regulación de los flujos migratorios temporales. En efecto, el acuerdo regula los flujos migratorios en las actividades donde labora la mayor parte de la población nicaragüense en Costa Rica (actividades agrícolas, agroindustriales y construcción), olvidándose sólo de una: el trabajo doméstico. Se puede explicar esta ausencia por ser más permanentes las migraciones en este sector, y sobre todo por las dificultades relacionadas con la inspección laboral, por el lugar donde se desempeña el trabajo: el hogar. Ahora bien, la inspección laboral es una actividad central en el acuerdo binacional de codesarrollo, ya que pretende vigilar los derechos de los trabajadores migrantes en todas las etapas de su experiencia migratoria. Sin embargo, se podría desarrollar el tema para el trabajo doméstico, replicando buenas prácticas de países receptores de migrantes, a fin de luchar contra los abusos que sufren trabajadoras domésticas y al mismo tiempo para desarrollar la fiscalización de este sector a gran escala.

Una iniciativa que se puede destacar es la de la Plataforma para la Cooperación Internacional sobre Inmigrantes Indocumentados (PICUM), una organización no gubernamental que tiene por objeto promover el respeto de los derechos humanos de los inmigrantes indocumentados en Europa. PICUM propone potenciar la inspección laboral al desviarla de su camino habitual, es decir que los inspectores no investiguen en el lugar de trabajo, ya que es privado, sino a partir del sistema de seguridad social y/o salud. Se supone entonces que para su buen funcionamiento, no sea relacionada la afiliación con el estatus migratorio: así la organización reporta que en el caso de España, se supone que cualquier persona puede registrarse y obtener una "Tarjeta Individual Sanitaria" que le permita acceder a los servicios de salud nacionales (PICUM, 2007). 


\section{Notas}

1 La Asociación de Servidoras Domésticas de Costa Rica fue creada en 1962 y destituida en el año 1972.

2 La Asociación de Trabajadoras Domésticas (conocida como ASTRADOMES) fue fundada en San José en el año 1991 por Rosita Acosta, quien es la presidente actual de la Asociación.

3 María del Carmen Cruz Martínez, Secretaria de la Junta Directiva y Promotora de ASTRADOMES, entrevista por la autora el 27 de agosto de 2010.

4 En conjunto con otras organizaciones no gubernamentales de la Red nacional de población migrante, como el Servicio Jesuita para Migrantes o el Centro de Estudios y Publicaciones Alforja (CEPS Alforja).

5 Se agradece especialmente los aportes de Karina Fonseca, Directora del Servicio Jesuita para Migrantes, Costa Rica; Tania Barrantes, quien coordinó el Proyecto "Protagonismo y empoderamiento de las mujeres migrantes nicaragüenses en Costa Rica" en el Centro de Estudios y Publicaciones Alforja; Róger Solórzano Alfaro, funcionario en la CCSS; Elberth Sancho, Asesor Jurídico en Migración, Dirección General de Migración y Extranjería de Costa Rica; y Berta Fernández, Jefa de Misión de la OIM en Nicaragua.

6 ASTRADOMES reporta testimonios de trabajadoras domesticas que se quejan de que sus empleadores les contestan que "están inventando".

7 Según tasa de cambio del Banco Central de Costa Rica el día 20 de octubre de 2010

8 Karina Fonseca, entrevistada por la autora el 19 de octubre de 2010

9 Tal como señala la CIDH a través de la Opinión Consultiva OC-18/03 "Condición Jurídica y Derechos De los Migrantes Indocumentados"

10 Las expresiones entre paréntesis reflejan las diferentes posibilidades para respectar la perspectiva de género.

11 Costa Rica ratificó el Convenio en 1960.

12 Adoptada por la Asamblea General en su resolución 45/158, del 18 de diciembre de 1990. Costa Rica no ratificó este instrumento.

\section{Referencias bibliográficas}

Asamblea Legislativa de Costa Rica. (2009a). Ley No 8726, Reforma del Capítulo Octavo del Título Segundo del Código de Trabajo, Ley No 2, Ley del Trabajo Doméstico Remunerado. La Gaceta No $^{0} 143$. Viernes 24 de julio de 2009. San José, Costa Rica, 2-3. Recuperado el 25 de agosto de $2010 \mathrm{de}$ http://historico.gaceta.go.cr/pub/2009/07/24/COMP_24_07_2009. pdf

Asamblea Legislativa de Costa Rica. (2009b). Ley General de Migración y Extranjería. Ley $\mathrm{N}^{\circ}$ 8764. La Gaceta $\mathrm{N}^{\circ} 170.1^{\circ}$ de setiembre de 2009. San José, Costa Rica. Recuperado el 25 de agosto de 2010 de http://historico.gaceta.go.cr/pub/2009/09/01/ COMP 01_09_2009.html

Asamblea Legislativa de Costa Rica. (2010). Adición de un párrafo final al inciso a) del artículo 105 del Código del Trabajo. Expediente $\mathrm{N}^{\circ}$ 17.689. La Gaceta $\mathrm{N}^{\circ}$ 156. Jueves 12 de agosto del 2010. San José, Costa Rica. 9. Recuperado el 25 de agosto de 2010 de http:// www.gaceta.go.cr/pub/2010/08/12/COMP_12_08_2010.html

Biffi, P. (2009). Costa Rica: Juntas somos más. Observador Global.com. Recuperado el 5 de agosto de $2010 \mathrm{de} \mathrm{http://observadorglobal.com/costa-rica-juntas-somos-mas-n1377.html}$

Contreras, P. (2006). Derechos laborales de las trabajadoras domésticas nicaragüenses en Costa Rica. Cuaderno Migratorio 9. Red Nicaragüense de la Sociedad Civil para las Migraciones. Managua: Edinter.

EIRENE. (2010). Migración de Retorno Nicaragua - Costa Rica - Nicaragua. Estudio Empírico, septiembre 2009. Managua: EIRENE \& Cenderos.

Fernández, B. \& Acosta, R. (2009). The Case of Domestic Workers in Costa Rica. Focal Point: Canada's Spotlight on the Americas, 8 (12), 18-19. Special Edition on Labour Mobility, 
Canada.

Goldsmith, M. (2007). Disputando fronteras: la movilización de las trabajadoras del hogar en América Latina. Femmes latino-américaines et migrations. Amérique Latine Histoire et Mémoire. Les Cahiers ALHIM. №14. Recuperado el 27 de agosto de 2010 de http://alhim.revues.org/index2202.html.

Guerrero, M.\&Lacayo, M. L. (2008).Instrumentos Normativos y mecanismos de protección y promoción de los derechos laborales de los trabajadores nicaragüenses en Costa Rica. Managua: Universidad Americana, Friedrich Ebert Stiftung.

Lerussi, R. (2008). Trabajadoras domésticas nicaragüenses en Costa Rica. En las encrucijadas de un debate feminista. Tesina de Magister en Género y Desarrollo no publicada. Instituto Complutense de Estudios Internacionales- Universidad Complutense de Madrid. España

Ministerio de Trabajo y Seguridad Social - MTSS. (2010). Fijación de salarios mínimos que regirán a partir del $1^{\circ}$ de julio de 2010. La Gaceta $N^{\circ} 133$. San José, Costa Rica. 2-3

Organización Internacional del Trabajo. (1958). Convenio relativo a la discriminación en materia de empleo y ocupación. $42^{\mathrm{a}}$ Conferencia Internacional del Trabajo. Ginebra

Organización Internacional del Trabajo. (1965). Resolución sobre Condiciones de Empleo de las Trabajadoras Domésticas. Boletín Oficial. Suplemento I. Conferencia Internacional del Trabajo, Sesión 49. Ginebra. 19-20.

Organización Internacional del Trabajo. (2006). Panorama Laboral 2006 América Latina y el Caribe. Lima: OIT - Oficina Regional para América Latina y el Caribe.

Organización Internacional del Trabajo. (2009). Panorama Laboral 2009 América Latina y el Caribe. Lima: OIT - Oficina Regional para América Latina y el Caribe.

Organización Internacional del Trabajo. (2010a). Trabajo decente para trabajadores del servicio doméstico: hacia unas nuevas normas internacionales del trabajo. Revista Trabajo, (68).

Organización Internacional del Trabajo. (2010b). Trabajo decente para los trabajadores domésticos. Informe IV (1) Cuarto punto del orden del día. Conferencia Internacional del Trabajo, Ginebra, 6 de marzo de 2010.

Paniagua Arguedas, L. (2007). Situación sociolaboral de la población nicaragüense en Costa Rica. Revista de Ciencias Sociales (Cr), (III-IV), 57-72.

Patiño, M., Solís, A. \& Galo, C. (2008). Estudio binacional (Nicaragua - Costa Rica) sobre la incidencia de la migración en las mujeres. Una lectura desde la perspectiva de las mujeres. San José, Costa Rica: Organización Internacional para las Migraciones / Fondo de Población de las Naciones Unidas.

Plataforma de Cooperación Internacional para Inmigrantes Indocumentados. (2007). Access to Health Care for Undocumented Migrants in Europe. Belgium: PICUM.

Fondo de las Naciones Unidas para la Mujer. (2010). La institucionalidad sociocultural y jurídica de la desigualdad: el trabajo doméstico remunerado: resúmenes de estudios de la región centroamericana y Republica Dominicana. San Salvador: UNIFEM.

Villegas, J. (2010, 23 de abril). Patronos de empleadas domésticas corren a asegurarlas ante nueva ley migratoria. La Nación, p.6. 